\title{
Consideration of Problem Formulation and Option Assessment for Bt cotton in Brazil
}

\author{
D.M.F. Capalbo, M.F. Simon, R.O. Nodari, S. Valle, \\ R.F. dos Santos, L. Coradin, J. de O. Duarte, J.E. \\ MiRANDA, E.P.F. Dias, Le QuANG QUYEN, \\ E. UNDERWOOD AND K.C. NELSON ${ }^{1}$
}

Corresponding author: Dr Kristen C. Nelson, Forest Resources/Fisheries, Wildlife and Conservation, University of Minnesota, 115 Green Hall, 1530 Cleveland Avenue North, St Paul, MN 55108, USA. Fax: +16126255212 , e-mail:kcn@umn.edu

\section{Introduction}

During the past decade, Brazil has been a hotbed of discussion over the benefits and risks of genetically modified organisms (GMOs). While critics question the contribution and safety of these organisms and proponents argue for their benefits, some scientists struggle to develop good evaluations of their potential beneficial and adverse effects. To contribute to the societal deliberation over GMOs, Brazil needs to develop an environmental risk assessment based on scientific information and analysis. In this chapter, we consider a model for problem formulation and option assessment (PFOA) as a cornerstone of environmental risk assessment. In a 3-day workshop session the authors were introduced to the idea of a PFOA in environmental risk assessment, considered the types of questions and characteristics of the process,

1 The authors and the participants of the PFOA discussion group at the workshop acknowledge Dr Maria José A. Sampaio of the Embrapa Secretariat for Intellectual Property Rights and Dr Ana Lúcía Assad of the Ministry of Science and Technology at the time of the workshop, for their contribution of ideas during the workshop. 
and made consensus recommendations about the value of a PFOA. Of particular interest in the Brazilian case study, the authors support findings from previous publications (Nelson et al., 2004), discuss how the PFOA might fit within existing Brazilian laws and regulations, and evaluate the staging of the PFOA as it blends with other components of a GMO's environmental risk assessment. The authors of this chapter have focused on science and environmental issues but recognize that others will need to be involved to understand how legal, ethical, social and economic issues can be included in risk assessment. The next step for a Brazilian team is to design the process for the PFOA based on a broader period of consultation and implement the PFOA within environmental risk assessment.

Since the global debate about the possible benefits and risks of GMOs has largely been framed by stakeholders from the developed world, governments in developing countries have found themselves in a dilemma. In some countries, a general apathy emerged and slowed adoption of GMO technology in agricultural systems. In many countries, political arenas provided the only avenue for debate, making it increasingly difficult to design effective and responsible GMO regulation that strikes a balance between safety and competitiveness, taking into account each country's unique context of society and ecosystems.

Certainly, transgenesis is a complex topic that embodies difficult technical, social and economic issues played out against a backdrop of human hunger, economic marginalization and environmental degradation (Traynor et al., 2002). In Brazil, transgenesis has not enjoyed the same acceptance by consumers as it has in the USA or Argentina, where it is viewed by some sectors of society as a major tool to aid in the development of agribusiness. Scientific, legal, ethical, environmental, social and economic issues are hotly debated. Concerns are also associated with complicated issues such as labelling, market barriers and global commerce. Media information sources are full of contradicting opinions from scientists, government authorities and citizen groups. Within this context, it is very difficult for Brazilian consumers to understand or trust any given comment or decision (Nutti et al., 2004, among others).

As a rule, the development of any novel technology emphasizes market issues. The current Brazilian situation indicates that the importance of safety issues associated with transgenesis will influence the path of development of transgenic crops; this path will follow a different route than technologies in other industrial sectors. Development of agricultural transgenic products will require consideration of other aspects, such as precise information about this new technology available to the consumer, with trustworthy scientific analysis as a reference point in the process.

Although experience has been acquired with products developed and commercialized in other countries, safety protocols should be developed and/or adapted to local conditions. In some countries there are limited monitoring and postharvest results (Department of Agriculture, Western Australia, 2004), but in most countries we lack this information. To ensure environmental safety, it will be necessary for each country to establish its own protocols, since results 
may differ from those already obtained in other regions of the world. Food and Agriculture Organization (FAO) officials emphasize this point in the following statement:

FAO supports a science-based evaluation system that would objectively determine the benefits and risks of each individual GMO. This calls for a cautious case-by-case approach to address legitimate concerns for the biosafety of each product or process prior to its release. The possible effects on biodiversity, the environment and food safety need to be evaluated, and the extent to which the benefits of the product or process outweigh its risks assessed. The evaluation process should also take into consideration experience gained by national regulatory authorities in clearing such products. Careful monitoring of the postrelease effects of these products and processes is also essential to ensure their continued safety to human beings, animals and the environment. ${ }^{2}$ (2004, p. 225)

The report goes on to recognize that there are few ecological studies in tropical areas and that more research will be necessary to address ecological risks in these areas. Brazil should review existing studies, using the findings when appropriate and establish its own robust research programme when necessary.

In 2003, a governmental decision unified the positions of the agencies regarding the necessity of health and environmental risk assessment analysis prior to large-scale GMO use. The prospect of increasing profits in major agricultural-commodity markets has prompted multinational companies to invest heavily in the acquisition of seed companies located in large Latin American countries such as Brazil. Consequently, major genes of economic importance that were used during the first wave of transgenic products in the USA and Europe are being transferred to Brazilian tropical varieties and are being experimentally tested in the country in accordance with the biosafety law passed in 1995 (Fontes, 2003). In June 2003, only one herbicide-tolerant (HT) soybean event had been approved for two planting seasons (2002/03 and 2003/04); approval was granted by the Brazilian National Congress because the decision-making authority of the National Technical Biosafety Commission had been challenged judicially. This Congressional approval was a temporary emergency measure to address the problems originating from illegal plantings of HT soybeans while the judicial challenge was pending. ${ }^{3}$

The focus of this chapter is motivated by two important concerns: (i) concern that premature release of GMO varieties will preclude critical steps

2 There is an active debate about whether anything can be or should be considered 'objective'. Stakeholder values are specifically not 'objective' and yet they are important components of the societal evaluation of risk. The authors have a worldview that science has something valuable to contribute to societal discussions, and to risk assessment in particular. The PFOA process is designed to include the broader societal discussion but enhance the way science informs this discussion.

3 The production and marketing of HT soybean has been authorized in the new biosafety law, as well as the planting of saved seed in the season 2004-2005. See Background on Brazil Biosafety Legislation for GM crops (this chapter). 
in environmental risk assessment; and (ii) the desire of Brazilian scientists and regulators for a carefully designed 'best science model' for the wise management of transgenic products. The challenge for chapter authors was to recognize and understand the conflicted nature of the GMO discussion in Brazilian society, while finding a common ground from which it is possible to move forward. In the PFOA model, multi-stakeholder participants have to formulate the problem that may be addressed by the GMO, as well as understand its scale and priority for society. Once this is accomplished the group has to compare possible options for solving the problem and evaluate the relative merit of the GMOs.

In Brazil, the science to assess GMOs is just beginning to be established as a foundation for review. As an example of one argument in the debate, Contini et al. (2003) used a simulation model to assess the potential economic benefits to the Brazilian economy resulting from unrestricted commercial approval of HT soybeans and other key crops. Model results indicated that economic benefits of legally adopting glyphosate-tolerant soybeans may be very high, and may also be significant for other transgenic crops such as maize and cotton. Contini et al. (2003) concluded that even though the country is fully capable of developing the necessary food-, feed- and environmental-safety tests, political and ideological reasons have prevented any legal commercialization of transgenic crops. Conversely, other scholars (Pelaez et al., 2004) concluded that transgenic HT soybeans are not more profitable than conventional soybeans. Overall, there are still insufficient scientific data to reach a common conclusion.

Some stakeholders believe government agencies in Brazil should have taken the lead to clarify legal requirements for research and commercial release of GMOs. In media reports, journalists highlight the concern that it was difficult for Brazilian researchers involved with biotechnology to accept the state of chaos and confusion created by the disputes between pro- and anti-GMO campaigners, while the illegal use of GM seeds emerged (Bonalume Neto, 2003). Clarifying regulations is the main objective of the new biosafety law.

While the societal discussion continues, farmers are making decisions about their production systems, and often pursue technologies that give them the best agricultural and economic returns. However, some stakeholders argue that a balance between environmental and human health concerns and competitive agricultural practices, including use of transgenic crops with high economic return, must soon be reached to avoid the growth of illegal planting areas (not only as occurred for glyphosate-tolerant soybeans). Another alternative small farmers are increasingly adopting is the agroecological approach, ${ }^{4}$ in which transgenic varieties are not part of the system. Compared with the traditional, conventional agricultural system or with systems that use transgenic varieties, the agroecological one can be more envi-

${ }^{4}$ In this case, the agroecological approach refers to a philosophy and system of farming that uses ecological principles, such as natural enemies, to guide decision making in production for a more sustainable system. 
ronmentally safe, because it strives to reduce the use of pesticides, and other negative environmental impacts such as soil erosion and nutrient runoff (Altieri, 2000). Recently, the 7th Conference of the Parties of Convention on Biological Diversity, held in Kuala Lumpur, 2004, approved a programme of work on the ecosystem approach to be adopted by parties across the world (CBD, 2004).

Despite the urgency of the scientific assessment to support safe agricultural technology, scientists want to carefully design appropriate research protocols and regulatory processes that will be received with confidence by decision makers and the general public. In a field with tremendous uncertainty, testing regimes can serve as a framework for improved understanding and analysis for public discussion. But how can each country come to its own agreement on an acceptable risk-assessment strategy? Critics argue that there has already been too much done with risk assessment. Brody (2002) argues that the money invested around the world in compliance and enforcement of biosafety rules, regulations and laws might be better spent in ways that would save many more lives. Others think we have only begun to understand what will be necessary in risk assessment. Some stakeholders argue for international standards in environmental protocols that would, at a minimum, harmonize requirements for similar cases and lead to better understanding of risk assessment, communication and management of GMOs. Such standards and assessment would differ dramatically from the more commonly known environmental-impact analysis done before construction of roads, dams or buildings.

The GMO Guidelines Project entered the Brazilian discussion with a workshop in June 2003, designed to encourage discussion among international and Brazilian scientists and regulators. ${ }^{5}$ The purpose of this discussion was to develop recommendations for environmental risk assessment protocols and processes that would serve as the basis for public deliberation and sound national decision making. This chapter represents consensus of the authors based on the workshop and subsequent discussions.

\section{PFOA Method 6}

PFOA is one cornerstone of GMO's environmental risk assessment. Countries must create a responsive system to facilitate socially acceptable choices (Stern and Fineberg, 1996). At its core, the discussion focuses on the critical societal need $^{7}$ that will be addressed by the GMOs, i.e. which needs will be satisfied and at what risk? Societal needs and risks require societal reflection. Countries

${ }^{5}$ For more on the scope, purpose and sponsorship of the GMO Guidelines Project, see the preface or visit the project website: http://www.gmo-guidelines.info

6 The PFOA method section has been modified from the original methods text in Nelson et al. (2004).

7 Societal benefits are distinct from societal needs in that they could be any positive contribution to the broader society, such as increased income or more choice, and based on different values. 
accept the possibility that something negative might happen with most major policy decisions but they never do so lightly. A deliberative process with multistakeholder participation allows members of society to participate in the evaluation of critical needs and risks. A cross section of society - farmers, consumer groups, industry, environmental representatives, policy makers, etc. - must have a vehicle to express their concerns and evaluate the future alternatives for addressing basic needs. Finally, this deliberative process ${ }^{8}$ will become increasingly important for resource-scarce nations if public investment is involved, because a comparative reflection by a cross section of society may be beneficial in prioritizing and targeting resources.

Given present uncertainties surrounding GMOs and regular reports of new discoveries about GMOs, the system to conduct a deliberative discussion should be flexible and able to respond to a society's core values, concerns and needs. At the same time, the discussion is best served if it is driven by sound, scientifically guided assessment and review (Gibbons, 1999; CBD, 2000; NRC, 2002). A robust environmental risk assessment clearly delineates when scientific knowledge, information and analysis can effectively respond to key questions and when it cannot.

In most natural-resource arenas, practitioners and scholars are implementing and evaluating diverse options for societal discussion about critical issues (O'Brien, 2000; Wondolleck and Yaffee, 2000). Specific contributions within the biosafety arena have detailed potential approaches to multi-stakeholder dialogues and participation (Skorupinski, 2001; McLean et al., 2002; Glover et al., 2003, Kapuscinski et al., 2003) and the evaluation of their key attributes (Irwin, 2001) at international and national scales. Societal discussion is advocated in setting priorities and strategies for agricultural research and development, in formulation of national biosafety frameworks and in environmental risk assessment of specific biotechnologies. A PFOA is applicable to all of these contexts, and can be employed in an iterative fashion to incorporate feedback from changing societal values and the scientific state of the art. In the Brazilian Bacillus thuringiensis (Bt) cotton case study presented in this chapter, PFOA creates the context for societal dialogue concerning the potential use of a proposed technology based on a transgenic organism such as Bt cotton. It is public deliberation about the transgenic organism that provides a rational, science-driven planning process by which multiple stakeholders can assess their needs, evaluate risks related to multiple future options, and make recommendations to decision makers about policies to reduce societal risks and enhance the benefits provided by various options.

Certainly the requirements set forth to accomplish a PFOA is a complex process - but this should not be considered as a possible argument against its use. Most important societal decisions are complex, messy and controversial, and because they are complex, messy and controversial we should work to improve them with transparent, systematic and scientifically based discussion. By doing so, the decision-making process gains social legitimacy and society

8 In this case a deliberative process refers to one based on an 'organized or careful discussion and debate'. 
gains greater confidence in the decisions taken. A PFOA can be used to provide such a discussion, and may play a significant role in environmental risk assessment.

\section{Relation of PFOA to environmental risk assessment}

Practitioners and scholars have tested numerous techniques that serve as a methodological foundation for the PFOA in environmental risk assessment (Grimble and Wellard, 1997; Kessler and Van Dorp, 1998; Schmoldt and Peterson, 1998; Biggs and Matsaert, 1999; Loevinsohn et al., 2002, to name a few). Two crucial steps in risk assessment are addressed by many of these techniques, and this PFOA model is designed specifically to address them. The first critical step in risk assessment is problem identification (NRC, 1983, 1996). What is the scope of the problem, how is it defined? Problem identification frames the entire risk assessment. A second critical step is the identification of potential alternative solutions to the problem (NRC, 1983, 1996). The proposed action - in this case, the use of Bt cotton in Brazil - is never the only possible way to address the problem. Risk assessment depends entirely on an appropriate specification of alternatives (including taking no action and doing nothing), so that comparative risk can be assessed, and appropriate controls for risk assessment science can be defined and used (see other chapters in this volume).

This PFOA model is comprised of specific brainstorming discussion and analytical components (Table 3.1). First, formulating the problem serves as the core foundation. The problem is defined as an unmet need that requires change (Goldstein, 1993). Basic human needs are most commonly identified as food, shelter and safety. Other human interests are stakeholder-specific such as enhanced economic opportunity, positive social interactions or cultural richness. For example, as a minimum foundation for well-being, individuals have a basic need for a certain amount of calories per day or the security that their children will continue to live healthy lives. Once the needs for food, shelter and safety are met, individuals can expand their interests to include numerous options for well-being. These interests will differ from one individual to another and from one group to another.

After a problem is identified, the PFOA model requires a comparative approach to risk assessment. The participants clarify the relative importance of this problem as compared to other problems or issues. Once the group agrees the problem is sufficiently important to merit an analysis, the range of future alternatives for solving the problem are compared in relation to their attributes, potential ability to address the problem, changes required to implement the option and potential adverse effects. The PFOA is planning for alternative futures, not for the current conditions against one option; rather, the PFOA makes a comparative assessment of alternative futures. After a complete analysis by a multi-stakeholder group, a recommendation is made to decision makers to continue research and development (in some cases risk-assessment research) with the technology or to halt the development of the technology. 
Table 3.1. Problem formulation and options assessment process.

\section{Initiating proposal}

\section{A. Proposal to use GMOs}

Any PFOA for transgenic organisms will be initiated by the request or suggestion that a particular GMO would be a beneficial alternative to the way things are currently being done in a particular cropping system.

\section{B. Decision by regulatory body}

Is there merit to moving forward to evaluate the GMO as a possible option or is the initiating proposal premature? Yes/No

PFOA process: questions to be answered by all representatives and shared in the deliberative process

\section{Step 1: Problem formulation}

\section{Formulation of problem \\ Basic human needs}

An unmet need that requires change
Food, shelter, safety

\section{Interests}

A stakeholder group's

values, goals and

perspectives

\section{A. Whose problem is it? Whose problem should it be?}

1. What needs of the people are not being met by the present situation?

2. What aspects of the present situation must be changed to meet the needs?

\section{Step 2: Prioritization and scale}

\section{A. Is this problem a core problem for the people identified?}

1. Do the people recognize the problem as important to their lives?

2. What are the potentially competing needs of these people?

3. How do the identified needs rank in importance to these other competing needs?

\section{B. How extensive is the problem?}

1. How many people are affected?

2. In what part of the country are these people located?

3. How large an area is affected by the problem?

4. How severe is the problem (local intensity)?

\section{Step 3: Problem statement}

Shared understanding of the unmet need and its relative importance for a particular group of people.

\section{Step 4: Recommendation by regulatory body}

Do we move forward to identify options and conduct and options assessment? 
Tatie 3.1. Problem formulation and options assessment process - cont'd.

Opion identification and assessment

\begin{tabular}{llll}
$\begin{array}{l}\text { Stes } 5 \\
\text { Options }\end{array}$ & $\begin{array}{l}\text { Step } 6 \\
\text { Characteristics }\end{array}$ & $\begin{array}{l}\text { Step 7 } \\
\text { Changes }\end{array}$ & $\begin{array}{l}\text { Step } 8 \\
\text { Effect on the system }\end{array}$ \\
\hline Future alternatives & For problem solving & Required/Anticipated & $\begin{array}{l}\text { Internal External } \\
\text { (Social, environmental, } \\
\end{array}$ \\
& & & economic) \\
\hline
\end{tabular}

Opion A

Opton B

Opton C

Etc.

\section{Step 5: Option identification}

Branstorm possible future alternatives to solve the identified problem; transgenic organisms would be one option. This step can be completed by the multiple stakeholder group for the initial identification of options. The multi-stakeholder group can do steps 6-8 or a technical committee can develop a report that covers steps 6-8 and the multi-stakeholder group can use the document to begin their evaluation of options and modify the assessment.

\section{Ster 6: Assessment of the options in relation to the problem}

Assessing capability of potential solution to solve problem.

1. What are the characteristics of the 'technology' option i.e. transgene, intercropping system?

2. What is the range of crop-production systems and what is the geographical region the option is likely to be used in or have an effect on?

3. What is the efficacy of the 'technology' on the target?

4. What are the costs of the technology within the crop-production system?

5. What barriers to use exist? For instance, is the seed-distribution system in place; can the potential solution be integrated into present production; can the farmers afford the potential solution?

6. How might the use of the option change cropping practices, such as tillage systems or pesticide use (including impacts on non-target pests)? What useful practices are renforced by the potential?

7. What information is needed to show that the changes are likely to occur? Baseline data associated with the diversity of present practices should be used if it is available.

8. How will anticipated changes in agricultural practices affect the needs identified in steps 1 and 2?

\section{Step 7: Changes required and anticipated for a specific option}

1. What changes in farm management practices might contribute to the solution?

2. What changes in the local community might contribute to the solution?

3. What changes in government support for farmers might contribute to the solution?

4. What changes in the structure of agricultural production might contribute to the solution?

5. What other changes would likely be needed to facilitate widespread use of this option? 
Table 3.1. Problem formulation and options assessment process - cont'd.

\section{Step 8: Adverse effects}

Potential adverse consequences from this option. Potential beneficial effects can be considered 'negative' adverse effects.

1. How might the potential solution affect the structure of agriculture or agricultural infrastructure?

2. How might the potential solution reinforce poor agricultural practices or disrupt useful practices?

3. What are the potential adverse effects of these changes internally and externally to the production system?

4. How will its use affect other nearby crop-production systems and non-agricultural environments (can its use be restricted to a particular cropping system or geographical region)?

5. Are any of these changes difficult to reverse, once they occur?

\section{Step 9: Recommendation}

The multiple stakeholder group should present their problem formulation and option assessment to the appropriate decision-making body.

A science-driven PFOA must be a deliberative process (Forester, 1999) designed to provide for social reflection and discussion about transgenic organisms. A sound deliberative process is transparent, equitable, legitimate and data-driven when possible (Susskind et al., 2000). Transparency allows for open communication of information between all parties and easily accessible reporting of decisions to the public (Hemmati, 2002). Providing an equitable PFOA process means that information from the broadest spectrum of society must be included with all stakeholders having the possibility to contribute. Civil society must perceive that there are sufficient avenues for input and consideration of diverse viewpoints and concerns. When transparency and equitable input are central to the process, the PFOA gains legitimacy in the public eye. This public legitimacy must be matched by traditional legitimacy or sanctioning by a formal political body that embeds the deliberative process. The deliberative process can be tied to a regulatory authority or legislative authority, but it must provide a means by which results from the PFOA inform government decision-making and action. Finally, the foundation of PFOA is a science-driven inquiry - in both environmental and social sciences. Questions are answered with data, impacts are assessed with valid indicators, and the limits of our understanding are clearly delineated by a research agenda or procedures for taking uncertainty into account.

Each country will need to develop a country-specific deliberative process that fits the particular structure and authority of the relevant decision-making bodies and implementing agencies. For many political systems in the world, the legitimating authority exists to incorporate PFOA in a legislative or regulatory context, but there are debates about necessary modifications of policies 
and regulation for transgenic organisms (Munson, 1993; Miller, 1994; Hallerman and Kapuscinski, 1995; Sagar et al., 2000; NRC, 2002). For some legislative or regulatory situations, a PFOA can be incorporated into a public consultative process that is authorized by regulation or it may be added as an alternative process supported by civic society that informs the debate in traditional decision-making bodies.

The following sections describe the regulatory background in Brazil, in order to facilitate the consideration of how a PFOA would best fit in the existing system in Brazil, and document a trial run of the PFOA model proposed for this risk assessment approach. It is not a PFOA for Bt cotton. It is an evaluation by the authors of the concepts and protocols for this PFOA model.

\section{Background on Brazilian Biosafety Legislation for GM Crops}

In an effort to assure society that care and precaution will be taken to warrant both environmental and human health safety of all food/feed produced from GMOs, Brazil has been working, for nearly a decade, to enact regulatory legislation. A brief report of the accomplishments so far is as follows.

\section{Past Brazilian biosafety legislation and the pressure for change}

Law no. 8974 of 1995: The superceded Brazilian Biosafety Law for GM crops involved regulatory agencies under three ministries. Each agency granted both special temporary testing permits and final licensing for commercial products according to their own rules and protocols. In addition, in the case of plants containing biopesticide traits, specific pesticide-control legislation also applied (Law no. 7802, of 1989), ${ }^{9}$ and Resolution 305 (June 2002) of the National Environmental Council (CONAMA) stated that GMO research and development are subject to the requirement of environmental impact studies - a preliminary step to any polluting activity.

The National Technical Committee for Biosafety (CTNBio) under the Ministry of Science and Technology, was given responsibility for assessment of health and environmental risks posed by GMOs. However, CTNBio's legal capacity to perform as stated in the Provisional Measure (PM) ${ }^{10}$ in 2001 has been repeatedly challenged judicially (the case in point was a CTNBio decision concerning glyphosate-tolerant soybeans). This challenge ended in August 2004 , with two judges voting to uphold and one voting to deny the CTNBio legal authority.

9 Pesticide Law no. 802/1989 and Decree no. 4.074/2002 available at http://www. planalto.gov.br

10 A Provisional Law Measure is a legal entity used by government when it needs any given law to go into force before it is submitted to the congress for approval. It is valid for 90 days and has to be voted and approved. 
Difficulties of the regulatory agencies in defining their own rules and protocols, coupled with the legal entanglements concerning CTNBio's mandate, resulted in a nearly complete halt of GMO research projects of plants producing biopesticide products from 2001 up to 2003. Particularly affected was research on virus-resistant GM plants. Confronted with this research crisis, the agencies sped up their protocols, and in September 2003, Brazilian Agricultural Research Corporation (Embrapa) was licensed to plant a GM papaya field trial in the north-eastern state of Bahía. In 2004, Embrapa was licensed to field test GM beans and GM potatoes. In all three cases, the transgene was designed for virus resistance. After these, private companies obtained licences to conduct similar research.

Resolution 305 (June 2002) of the National Environmental Council $(\mathrm{CONAMA})^{11}$ stated that GMO research and development are subject to the requirement of environmental impact studies - a preliminary step to any polluting activity.

Labelling: Decree no. 4680 (April 2003) guarantees the right of information - as established in the Brazilian Consumers Defence Law (Law no. 8.078 of 1990) - compelling the labelling of every food that contains more than $1 \%$ of a GM ingredient. It also determines that animals that have been fed with transgenic grains, as well as the products prepared with the animals' meat, milk and eggs must be labelled. Practical difficulties in Brazil will make this labelling statute difficult to implement effectively.

\section{The new biosafety law}

Dissatisfaction with the ambiguities in the present legislation and the consequent difficulties to research led the government to submit a new bill to Congress, in November 2003, which was passed and signed by the president on March 24 2005. ${ }^{12}$

The new law covers licensing for laboratory, greenhouse, and field experiments, and applications in the areas of agriculture, environment and health. It assigns authority to $\mathrm{CTNBio}^{13}$ for issuing technical opinions, case-by-case, on both research-related activities and the commercial use of GMOs and their byproducts. The CTNBio opinion is forwarded to the registration and inspection agencies - SDA (Plant Protection Secretariat, Ministry of Agriculture), IBAMA (Brazilian Institute for the Environment, Ministry of Environment), and ANVISA (National Agency of Sanitary Control, Ministry of Health). The agencies are responsible for inspection and monitoring in their respective areas. They are

11 Available at: http://www.mma.gov.br/port/conama/index.cfm

12 An English translation of the law is available at: http://www.ctnbio.gor.br/index. php?action=/content/view\&cod_objeto $=1296$

13 The new CTNBio will be composed of 27 experts: 12 scientific experts in the areas of human health, animal health, plant health and environment, nine Ministry representatives, including the three regulatory Ministries, and six other experts chosen by specific ministries for specific areas of expertise. 
bound to CTNBio's opinion, and in the case of research, CTNBio is expressly given final authority. However, whenever there is dissension regarding CTNBio's technical opinion on commercial use of a GMO, the registration and inspection agencies can appeal. The final decision on commercialization then lies with the new National Biosafety Committee (CNBS), made up of 11 ministers and subject to the Office of the President of the Republic. The CNBS can also, upon CTNBio's request, analyse the socio-economic convenience and opportunities and national interest entailed in the requests for commercial use.

At the time of writing, the rules governing the operation of the expanded CTNBio and the CNBS are still being discussed and it is unclear how the law will function. One recent decision taken by the old CTNBio related to importation of $\mathrm{Bt}$ maize varieties for animal feed ${ }^{14}$ has been suspended by the CNBS, allowing just the three events analysed by CTNBio (gen Cry1Ab, Cry $1 \mathrm{Ac}$ and $\mathrm{Cry} 9 \mathrm{C}$, for insect resistance; gen pat and bar, for glyphosinate herbicide tolerance; and gen $m E P S P S$, for glyphosate herbicide tolerance) to be imported. ${ }^{15}$ Two other decisions of the old CTNBio that required analysis by CNBS have not yet been delivered: on commercialization of Bollgard Bt cotton and transgene contamination limit in cotton seed. ${ }^{16}$

\section{Provisional measures}

The increase in illegal planting of GM soybean and the delays in the judicial decision prompted the government to issue two PMs: PM 113 and PM 131. The first one was issued specifically to legalize marketing of GM soybean harvested in the early months of 2003 , while the second was to legalize, for only 1 year, the 2003/04 planting and marketing of transgenic soybean seeds retained from the previous harvest. The production and marketing of HT soybean has been authorized in the new biosafety law, as well as the planting of saved seed in the season 2004/05. Since then, various HT soybean varieties have been brought onto the market in Brazil.

\section{A consensus proposal}

At another scale, the international forecast for the implementation of the Cartagena Protocol on Biosafety, which came into force in September 2003, but really gained momentum after the first meeting of the parties that took place in Malaysia, February 2004, implies that all signers will need to have risk-assessment regulations in place. Brazil became a party to the Cartagena Protocol in February 2004 and has not yet developed all the procedures required for export and import of GM products.

${ }_{14}$ Available at: http://www.ctnbio.gov.br/index.php?action=/content/view\&cod_objeto= 1305 (English version) or http://www/ctnbio.gov.br/index.php?action=/content/view\& cod_objeto=1299 (complete, Portuguese version)

15 Source: Technical note from Dr Mônica Amâncio, lawyer.

${ }^{16}$ Source: http://www.prdf.mpf.gov.br 


\section{Bt cotton in the Brazil regulatory system}

Regarding government decisions specific to the present case study, Bt cotton varieties owned by multinational companies were granted approval from the CTNBio for field trials beginning in 1997, in various regions of Brazil. These varieties produce the proteins Cry $1 \mathrm{Ab}, \mathrm{Cry} 1 \mathrm{Ac}$ and Vip3A, and one variety contains both Cry1Ab and Cry1Ac. In 2000, a court injunction suspended these tests until they were granted approval by other Brazilian regulatory agencies. During the years 2001-2005, the companies did not receive approval for new field trials. On March 18 2005, the old CTNBio made a recommendation to commercialize Bt cotton containing Bollgard event 531. Their decision has been suspended by the CNBS and is being examined.

\section{Test Run for the PFOA Model in the Brazil Case Study for Bt Cotton}

The authors evaluated the PFOA model by discussing its purpose within an environmental risk assessment, testing a few questions from each step in the model to experience the type of discussion that might result from a multistakeholder exchange (Table 3.1), and deliberating over how a PFOA would best fit in the Brazilian regulatory system. The authors then summarized their findings about the PFOA content and process within the context of Brazil's deliberation over Bt cotton.

After discussing the questions in steps 1 and 2 (Table 3.1), the authors came to a consensus on the following problem statement for cotton pest problems.

\section{Problem statement}

During periods of high infestation, Lepidopteran pests cause yield reductions in cotton, increasing the number of insecticide applications and consequently increasing the cost of cotton production, possibly affecting the health of farmers and people who are involved with the crop, also causing environmental pollution in the soil and water systems. Reduced stability of yield makes planning more difficult and risky.

In the North-east, for small-scale farmers, the boll weevil damages cotton during the rainy season (March-May). Lepidopteran pests are not a major problem.

In the Midwest and Meridian regions, Lepidopteran pests are a moderate to major problem.

Continuing the test run of the PFOA model, we conducted a brainstorming session about possible options for addressing the problem. The options included Bt cotton, insecticide applications, biological control with Trichogramma wasps, integrated pest management (IPM) packages and organic packages. We selected Bt cotton, biological control (wasps) and 
insecticide applications as options used to evaluate questions in steps 6-8. Overall, our conversation jumped around a great deal, but participants developed a sense of the type of discussion produced by the questions and where the difficulties would emerge.

\section{Evaluation of a Brazil PFOA}

After reviewing the PFOA model and discussing the Kenya case study, the Brazilian authors agreed with their Kenyan counterparts on five key findings (Nelson et al., 2004) and refined them in several aspects.

Finding \#1: PFOA is a good idea for any agricultural technology but critical for GMOs. It should be done taking into consideration a precautionary approach on a case-by-case basis.

Finding \#2: PFOA proved to be particularly useful for encouraging constructive dialogue and potential agreements.

Finding \#3: For a successful PFOA, a nation should have in place a regulatory framework that would allow for the reduction of uncertainty about GMOs. Consideration of the PFOA could help to initiate discussions about possible regulatory options.

Finding \#4: The discussion of a case study provides applied insights about key issues and consensus building.

Finding \#5: Additional questions will strengthen the PFOA: what loss has occurred as a result of the problem in productivity as well as environmental, social and economic aspects? How will the technology's use affect the environment? How will use of the technology affect the conservation of genetic variability of the species and other related biodiversity?

We find there is a demand for a new way to host societal discussions, just as scholars have documented the need for creative approaches to critical natural resource-problem solving and risk assessment in other countries (O'Brien, 2000; Wondolleck and Yaffee, 2000). The use of a PFOA process in environmental risk assessment for GMOs provides a framing of the risk-assessment stages, allowing diverse stakeholders in the PFOA to propose issues that need to be evaluated in the risk-assessment stages, as well as serve as a multi-stakeholder discussion that can use the scientific results from the assessment to inform their evaluation of the options. The uncertainty associated with GMOs as an alternative make a PFOA process critical, so multiple stakeholders can contribute their views and science is used to inform the discussion.

Due to the nature of the GMO discussion, and the absence of sufficient scientific biosafety data in Brazil and monitoring data after release of new products or techniques in other countries, several authors believe it would be necessary to take a precautionary approach for each GMO technology. A precautionary approach, as represented in European regulation, balances between the need to take action and scientific uncertainty (Skorupinski, 2004), with the philosophy that if there is a 'reasonable assumption of possible harm' then the government should take measures for protection (CEC, 2000). Certainly, Brazil will need to develop its own understanding of the precautionary approach. 
In particular, the options assessment would have to include more specific questions about environmental risks and a well-documented analysis of the crop losses a new technology would address. The adoption of a new technology might cause changes in environmental and societal aspects, which are not necessarily explicit. Purely economic questions should not obscure other aspects related to the problem. We must also consider the entire ecosystem involved, as well as the consequences for human health and well-being. For example, in the past some newly introduced technologies in a production system (e.g. chlorofluorocarbons (CFCs), pesticides) largely served to produce economic gains for multinational companies, but without regard for other consequences that could alter the components of the water-soil-atmosphere system and its relationship with living organisms.

The authors (a diverse group of ministry officials) believe a PFOA model would be useful for constructive dialogues, new insights and the consensus building necessary for possible agreements in Brazil, a finding supported by studies of multi-stakeholder dialogues in other countries (Irwin, 2001; McLean et al., 2002; Glover et al., 2003). Even in the highly politicized debates about Brazil's use of GMOs, we see some promise in a guided discussion about the range of issues in the societal consideration of a new genetically engineered product.

National governments are often critical actors for facilitating socially acceptable choices (Stern and Fineberg, 1996). Fundamental to the conceptualization of a Brazilian PFOA is the understanding that it has to be embedded in the regulatory systems in such a way that it reduces uncertainty for all members of society. At its best, it would serve as a forum for all stakeholders to understand the problem that needs to be addressed and the comparative impact of different options for solving the problem. In the Brazilian context, the PFOA would have to be organized by government authorities, but provide a forum that is viewed as legitimate by the multiple stakeholders. Representatives of these diverse stakeholders would have to have a voice and believe they had some influence in the assessment of options. This argument for transparency, equity, legitimacy and a data-driven process is well supported in the literature (Susskind et al., 2000; Hemmati, 2002).

Many countries are considering modifications of policies and regulation for transgenic organisms (Munson, 1993; Miller, 1994; Hallerman and Kapuscinski, 1995; Sagar et al., 2000; Burachik and Traynor, 2002; NRC, 2002; UNEP-GEF, 2003a,b). Because Brazil already has a complex system of laws and regulations, the authors suggest the following broad guidelines.

Finding \#6: The PFOA should be organized by government authorities and discussed by a multi-stakeholder group.

Finding \#7: In Brazil, the PFOA should be embedded in the policy and regulatory process.

Finding \#8: In Brazil, PFOA staging can involve two meetings.

One option for incorporating the PFOA in the existing system would be to associate it with the CTNBio, but some modifications will be necessary (Figs 3.1 and 3.2). In 2003, the members of CTNBio were predominantly biotechnical scientists. In the future, this membership should be broadened 


\section{GMO \\ proposal}

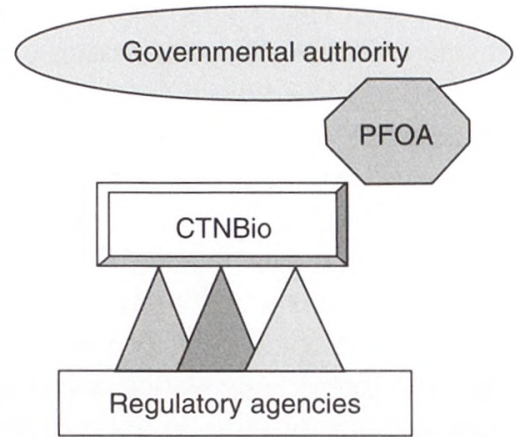

Fig. 3.1. Suggestions for embedding the problem formulation and option assessment (PFOA) in the Brazilian regulatory system. Three ministries (Environment, Agriculture and Health) and the National Technical Biosafety Commission (CTNBio, Science and Technology Ministry) play a role in the final decision for environmental release of a genetically modified organism (GMO).

Stage 1. Based on GMO proposal, the first PFOA meeting is facilitated by government authorities and carried out by a multi-stakeholder group.

Stage 2. CTNBio receives the registrant's proposal and the PFOA report. For a review of this report a composition of the CTNBio should be broadened in scientific expertise and stakeholders.

Stage 3. If the decision is favourable, it is sent to the ministries of Environment, Health, and Agriculture.

Stage 4. The proponent asks for respective licences from the ministries for laboratory, small- and large-field trials.

Stage 5. PFOA second meeting called to review the assessment in light of new results from testing.

Stage 6. The appropriate ministries review the PFOA report, promote public comment period, and may ultimately authorize for commercial use.

in scientific expertise in order to have the capacity to evaluate the results from a PFOA report that includes economic, social and environmental recommendations.

The CTNBio would receive the registrant's proposal of a transgenic organism; this may come from a private company or federal research institute such as Embrapa. CTNBio would decide if there is sufficient consideration for biosafety in the proposal to consider it for use in Brazil. If the proposal has been accepted for consideration, the CTNBio would convene the PFOA multi-stakeholder group for a first meeting to consider problem formulation (steps 1-2), and an initial review of options assessment including information needed for a full consideration of steps 6-8. The CTNBio would receive the registrant's proposal and the PFOA preliminary report and decide on whether to continue environmental risk assessment. If the decision is favourable, it is sent to the ministries of Environment, Health and Agriculture. The proponent asks for respective 
licences from the ministries for laboratory as well as small- and large-scale field trials. Near the end of field trials, the second PFOA meeting is called to review the assessment in light of new results from testing. The report will define the problem and its scope and compare the options. It will represent the degree of consensus among the stakeholders on important issues as well as the range of opinions expressed. Finally, the appropriate ministries review the PFOA report, conduct a public hearings session, and decide if the GMO should be authorized for commercial use. In all cases, the PFOA meetings would be guided by a predetermined process, but sufficient flexibility needs to be allowed to respond to the unique characteristics of each case.

The staging of the PFOA process is particularly important because it must be designed to provide guidance for other sections of the environmental risk assessment, but at the same time the PFOA process needs to be informed by scientific results from the studies conducted by other sections (Figs 3.1 and 3.2). The first PFOA meeting could be held prior to risk-assessment studies to help understand the problem, provide a preliminary review of options and highlight critical societal concerns. Then studies can be conducted during the following stages in the development of a transgenic plant (Andow et al., Chapter 1, this volume): (i) the design of transformation; (ii) focusing on set of events; (iii) characterization (laboratory and greenhouse); (iv) small-scale planned field trial; and (v) precommercialization. The second PFOA meeting should be conducted when laboratory and field environment biosafety test results can be included in the process.

The societal discussion about critical issues, specifically GMOs, is best served if it is driven by scientifically guided assessment and review (CBD, 1992; Gibbons, 1999; NRC, 2002), as well as consideration of the social, economic and ethical concerns. This is also true for any PFOA process. Brazilian workshop participants emphasized that existing data and studies required by the environmental risk assessment would be necessary for a scientifically guided review. This also complies with the Cartagena Protocol on Biosafety.

Brazil has the scientific capacity to support a PFOA process and, if funds are allocated, the resources to conduct the multi-stakeholder dialogue. As the process is developed, there will always be a tension between efficiency in costs and time versus adequate coverage in representation and the extensiveness of the deliberation. There will be start-up costs in developing the process and organizing adequate reporting systems for information. In Brazil, many agency staff and stakeholder representatives will require capacity-building assistance to facilitate or participate in a PFOA. Though Brazil may have the resources to contemplate a more elaborate process, other countries may need to develop more streamlined processes that still encourage discussion.

Finding \#9: A database of existing studies should be organized and integrated to support PFOA discussion as needed.

Brazil has a wide variety of information sources to support steps 1-8 of the PFOA, but data about existing technologies in the agricultural sector are frequently spread among several institutions. This information would be very useful for questions about production problems and related issues, however, it is often hard to find or difficult to interpret. In other cases, the required 


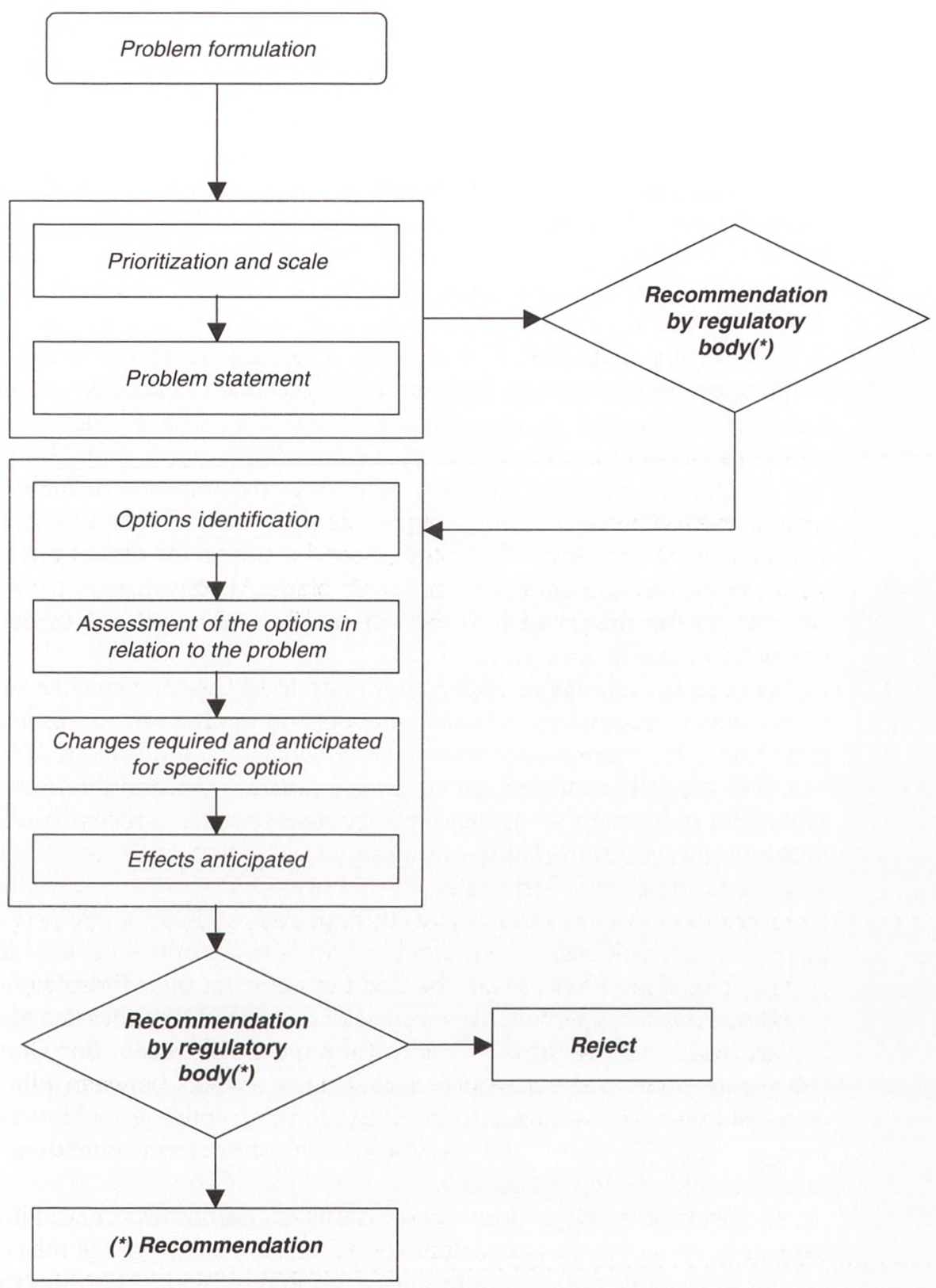

Fig. 3.2. Schematic workflow for the problem formulation and option assessment (PFOA) process. The regulatory body still needs to be defined by Brazilian authorities. ( ${ }^{*}$ indicates involvement of the recognized authority within the country. This authority receives the PFOA document and decides how to proceed.) 
information is not available and it would be necessary to conduct additional surveys. Overall, for efficient problem formulation (steps 1 and 2) it would be necessary to establish a database where the information from several sources (census statistics, existing studies including economic, social, etc., papers and surveys) can be organized and integrated in a way that every person can understand it. When no studies exist, an inclusive research agenda should be developed to fill critical gaps using available resources, working to enhance the multi-disciplinary nature of data over time.

First, an inventory of all existing data sources will be required, such as the agricultural census, statistical yearbook, scientific database and botanical review. For example, the 1996 agricultural census produced by the Brazilian Institute for Geography and Statistics (IBGE) identified 93,688 rural establishments involved in cotton cropping in Brazil. In recent years, there has been a significant change in the location of the cultivated area in Brazil, with a shift from the North-east and Meridian regions to the Midwest and the western part of Bahía (Fontes et al., Chapter 2, this volume). These changes had implications for the technological matrix and producer profiles, from the limited capital-intensive approaches of small farmers to the higher technological level of commercial farmers. Therefore, updated information is important for a PFOA analysis of Bt cotton.

In general, a literature review and new research efforts will be necessary at a regional level to provide information and analysis for consideration in steps 6-8. These studies will have to be conducted by a reliable scientific institution. A general producers' survey is recommended to identify needs prioritization and projections of demand. For Brazilian cotton, a recent survey in the Midwest and part of the North-east (west of Bahía state) will supply some data relevant for a problem formulation.

Some data can be obtained from the literature about contained environment research on GMOs. In addition, new research approaches and field data at the regional level have to be assessed to determine the barriers to use, environmental impacts (see Chapters 6 to 12, this volume), marketing issues and human health aspects of the GMOs, to name a few areas. For Brazilian Bt cotton, information about efficacy and cost are available from private companies, but these data will need to be reviewed by scientists in public institutions (Grossi et al., Chapter 4, this volume). In the short term, published findings from abroad have to be assessed.

In the case of Bt cotton, gene flow is of particular concern for Brazil because there are three native cotton species in which cross hybridization and hybrid formation with cultivated varieties has already been documented. Further scientific studies will be necessary to evaluate introgression and genetic contamination effects (Johnston et al., Chapter 11, this volume). In addition, Brazil hosts a rich biodiversity with more than a million insect species.

Finding \#10: PFOA serves as a good foundation for future monitoring of environmental and societal impacts of the technology.

Once a particular option has been accepted by the decision makers, its implementation and impacts will have to be monitored to identify possible shifts in the environment and society. The participants recommended that the nation develop systems for monitoring new technologies, and consider the 
PFOA model as an approach that can be adapted to postrelease monitoring as well as prerelease evaluation.

\section{Next steps in the design of a Brazilian PFOA}

In the 3-day workshop session the authors were introduced to the idea of a PFOA in environmental risk assessment, considered the types of questions and characteristics of the process, and made consensus recommendations about the value of a PFOA. The next step for a Brazilian team is to design the PFOA process based on a broader period of consultation and then implement the PFOA within environmental risk assessment. Brazil needs to develop its own PFOA process. There are many documented experiences of multi-stakeholder processes that can serve as a resource bank, as well as numerous techniques to facilitate discussion and option assessment (Crowfoot and Wondolleck, 1990; Susskind et al., 1999; to name a few). More details about how multi-stakeholder dialogues have been applied in the consensus-building process in other countries would help the designers' understanding of how the PFOA might be applied. As a foundation, it would be very helpful to have a handbook that synthesizes this literature in light of the PFOA process for environmental risk assessment of GMOs. Many of the tools are publicly accessible on websites and through publications, but they are dispersed across organizations, agencies, countries and continents. A training handbook could guide the Brazilian design team through the major design issues and link them to ways others have addressed these issues. It would also serve as a reference as other countries develop their own PFOA for environmental risk assessment, or as a support tool for training regulators and stakeholders in the process. Overall, PFOA may be one component of a broader public-participation strategy for biosafety issues.

There are several critical issues that will need to be addressed while designing the Brazilian PFOA process. The keys to building a credible consensus on a science-intensive policy question are: (i) perceptions about the fairness of the method used to select stakeholder representatives who are invited to participate in a multi-stakeholder dialogue; (ii) the management (by a professional 'neutral') of the complex give and take involved in such a process; and (iii) the preparation of a written report - embodying the discussion and degree of consensus that will inform decision makers. The following represents a few issues and questions that will need to be considered, but this list is by no means exhaustive.

\section{Independence and legitimacy}

In the case of GMOs, PFOA is a needed tool for orienting scientific analysis of risks, and for addressing the conflict of questions of interest related to the subject. As with any other method, however, it can be manipulated depending on how different tendencies and expertise are represented. As stated in the findings section, a government authority, possibly CTNBio, should convene the PFOA, but there are still many decisions to be made about how to identify and invite stakeholders. The goal should be to balance the interests of all relevant stakeholders 
with the need to generate a credible analysis of the parties involved (Crowfoot and Wondolleck, 1990). Also, its results and reports can be used to inform and help decision makers to make decisions based on scientific analysis of the environmental, social, ethical and economic risks posed by GMOs, or they may just be used to legitimate a priori decisions enforced by the lobby or pressure groups. It all depends on how independent and public the process will be.

One of the principal requirements for public legitimacy of the proposed PFOA process is independence. As pointed out in previous sections, if the host regulatory agency and the decision-making body are dominated by probiotech representatives or anti-biotech representatives, it could become one more tool for legitimating biased decisions. Designers of the process will have to carefully address:

- how to guarantee independence

- how to guarantee that conflicting interests will be represented

- how to use techniques for identifying relevant stakeholders

- how to assure legitimacy of selected representatives

- how to finance PFOA in environmental risk assessment

- how to prepare participants with information

\section{Evaluating stakeholder contributions and comparing options}

PFOA designers will have to consider how diverse stakeholder contributions can be made in an open discussion without judgement, but at the same time use agreed upon criteria for managing information, scientific findings and diverse values. For example:

- how to identify a neutral party to facilitate the process

- how to establish ground rules to govern the dialogue

- how to pay attention to disparities in power and the ability of different stakeholders to participate fully

- how to enforce that trustful risk-assessment analysis will be carried out when, and where necessary, and for the time it is necessary

- how to guarantee the transparency of the deliberation

- how to manage information so it is timely and accessable

- how to deal with a lack of consensus between experts

- how to guarantee that information produced will be released to the public

- how to assess the effectiveness of the participatory process

\section{Linking recommendations to decision making}

Finally, a written report about the PFOA deliberation will have to represent the critical issues, the degree of consensus and the range of opinions. Special attention will need to be paid to:

- how to present recommendations if there is no consensus

- how to take the results of the deliberation into the decision-making process in a timely manner

- how to recognize the conclusions of government authorities 


\section{Conclusion}

The rapid advances in modern biotechnology, particularly genetically engineered products, will shape the coming decades of economic development. As more transgenic products are field tested and eventually approved for commercialization, scientists will also learn more about how to manage the possibility that something negative might happen, the risks and the socio-economic implications. In addition, a new array of possibilities is emerging from data obtained from functional genomics, and its potential impact on the sustainability of agricultural production could be enormous. As more developing countries begin to evaluate the local applications of the technology, each country will have to develop its own approach for societal discussion. Some members of society may begin to accept GM varieties as simply obtained by a different biological process, while others may take principled positions against technologies that have the potential for irreversible harm to the environment. Still others may use a holistic approach for the safe use of genetically engineered products, taking into account social, economic and ethical values.

For the last 15 years in Brazil, a range of other issues have been associated with the use of some biotechnology, mainly transgenic organisms and human and animal cloning, in such a way that political, economic, social, scientific and ethical issues are part of discussions throughout the country. Questions exist due to the lack of scientific, social, economic and environmental impact studies. Citizens also wonder about intellectual property rights, the build-up of gigantic transnational companies with focused influence around the world, and unresolved ethical, economic and social issues.

The coming years will be a challenging period for developing countries as they address issues such as the need for better training of scientists (including in the areas of risk assessment and monitoring of GM experiments) and inhouse investments needed to continue the development of their capacity in the area of biosafety.

A societal multi-stakeholder discussion such as PFOA can strengthen the consideration of critical problems, the options we have for addressing them, and the role biotechnology and biosafety will play. We hope the coming years will give scientists greater confidence in developing appropriate methods to predict, or at least properly assess, the possible negative environmental impacts on a case-by-case basis and that a science-based discussion will inform public choices and allow these choices to be considered within the decision-making process.

\section{References}

Altieri, M.A. (2000) The ecological impacts of transgenic crops on agroecosystem health. Ecosystem Health 6, 13-23.

Biggs, S. and Matsaert, H. (1999) An actor-oriented approach for strengthening research and development capabilities in natural resource systems. Public Administration and Development 19, 231-262. 
Bonalume Neto, R. (2003) GM confusion in Brazil. Nature Biotechnology 21, 1257-1258.

Brody, J. (2002) In a world of hazards, worries are often misplaced. New York Times, August 20.

Burachik, M. and Traynor, P.L. (2002) Analysis of a National Biosafety System: Regulatory Procedures in Argentina. ISNAR Country Report 63, International Service for National Agricultural Research, The Hague, The Netherlands.

CBD (Convention on Biodiversity) (1992) Convention on Biodiversity: convention text. Available at: http://www.biodiv.org/doc/legal/cbd-en.pdf (accessed February 2005).

CBD (Convention on Biodiversity) (2000) Cartagena Protocol on Biosafety: convention text. Available at: http://www.biodiv.org/biosafety/protocol.asp (accessed October 2003).

CBD (Convention on Biodiversity) (2004) Decision VII/11. Available at: http://www. biodiv.org (accessed February 2005).

CEC (Commission of the European Communities) (2000) Communication from the Commission on the Precautionary Principle, COM (2000) 1 final. Available at: http://europa.eu.int/comm/environment/docum/20001_en.htm, CEC, Brussels, Belgium (accessed October 2004).

Contini, E., Sampaio, M.J.A.M. and Ávila, F. (2003) The lack of clear GMO regulation and its costs for the Brazilian economy. International Journal of Biotechnology 5. Available at: http://www.environmental-expert.com/magazine/inderscience/ijbt/ (accessed October 2004).

Crowfoot, J.E. and Wondolleck, J.M. (1990) Environmental Disputes: Community Involvement in Conflict Resolution. Island Press, Washington, DC.

Department of Agriculture Western Australia (2004) GMO Trial Details. Available at: http://agspsrv34.agric.wa.gov.au/biotechnology/gmtrials.htm (accessed November 2004).

FAO (2004) The state of food and agriculture 2004. Agricultural biotechnology: meeting the needs of the poor? FAO Agriculture Series, No. 35. Rome, Italy.

Fontes, E.M.G. (2003) Legal and regulatory concerns of transgenic plants in Brazil. Journal of Invertebrate Pathology 83, 100-103.

Forester, J. (1999) The Deliberative Practitioner: Encouraging Participatory Planning Processes. MIT Press, Cambridge, Massachusetts.

Gibbons, M. (1999) Science's new social contract with society. Nature 402, C81-C84.

Glover, D., Keeley, J., McGee, R., Newell, P., Da Costa, P., Ortega, A.R., Loureiro, M. and Lin, L.L. (2003) Public Participation in National Biosafety Frameworks: A Report for UNEP-GEF and DFID. Institute of Development Studies, Brighton, UK.

Goldstein, I. (1993) Training in Organizations, 3rd edn. Brooks/Cole Publishing Company, Pacific Grove, California.

Grimble, R. and Wellard, K. (1997) Stakeholder methodologies in natural resource management: a review of principles, contexts, experiences and opportunities. Agricultural Systems 55(2), 173-193.

Hallerman, E.M. and Kapuscinski, A.R. (1995) Incorporating risk assessment and risk management into public policies on genetically modified finfish and shellfish. Aquaculture 137, 9-17.

Hemmati, M. (2002) Multi-Stakeholder Processes for Governance and Sustainability: Beyond the Deadlock and Conflict. Earthscan, London.

Irwin, A. (2001) Constructing the scientific citizen: science and democracy in the biosciences. Public Understanding of Science 10, 1-18. 
Kapuscinski, A.R., Goodman, R.M., Hann, S.D., Jacobs, L.R., Pullins, E.E., Johnson, C.S., Kinsey, J.D., Krall, R.L., La Viña, A.G.M., Mellon, M.G. and Ruttan, V.W. (2003) Making safety first a reality for biotechnology products. Nature Biotechnology 21(6), 599-601.

Kessler, J. and Van Dorp, M. (1998) Structural adjustment and the environment: the need for an analytical methodology. Ecological Economics 27, 267-281.

Loevinsohn, M., Berdegué, J. and Guijt, I. (2002) Deepening the basis of rural resource management: learning processes and decision support. Agricultural Systems 73, 3-22.

McLean, M.A., Frederick, R.J., Traynor, P.L., Cohen, J.I. and Komen, J. (2002) A conceptual framework for implementing biosafety: linking policy, capacity and regulation. International Service for National Agricultural Research Briefing Paper 47, ISNAR, New York.

Miller, H.I. (1994) A need to reinvent biotechnology regulation at the EPA. Science 266, 1815-1818.

Munson, A. (1993) Genetically manipulated organisms: international policy-making and implications. International Affairs 69, 497-517.

NRC (National Research Council) (1983) Risk Assessment in the Federal Government: Managing the Process. National Academies Press, Washington, DC.

NRC (National Research Council) (1996) Understanding Risk: Informing Decisions in a Democratic Society. National Academies Press, Washington, DC.

NRC (National Research Council) (2002) Environmental Effects of Transgenic Plants: The Scope and Adequacy of Regulation. National Academies Press, Washington, DC.

Nelson, K.C., Kibata, G., Lutta, M., Okuro, J.O., Muyekho, F., Odindo, M., Ely, A. and Waquil, J. (2004) Chapter 3: Problem formulation and options assessment (PFOA) for genetically modified organisms: the Kenya case study. In: Hilbeck, A. and Andow, D.A. (eds) Risk Assessment of Transgenic Crops: A Case Study of Bt Maize in Kenya. CAB International, Wallingford, UK, pp. 57-82.

Nutti, M., Sampaio, M.J.A.M. and Watanabe, E. (2004) GMO research and agribusiness in Brazil: impact of the regulatory framework. In: Taylor, Iain E.P. and Barrett, K. (eds) Genetically Engineered Plants: Decision-Making under Uncertainty. Haworth's Food Products Press, Binghamton, New York.

O'Brien, M. (2000) Making Better Environmental Decisions: An Alternative to Risk Assessment, 3rd edn. MIT Press, Cambridge, Massaschusetts.

Pelaez, V., Albergoni, L. and Guerra, M.P. (2004) Soja transgênica vs. soja convencional: uma análise comparativa de custos e benefícios. Cadernos de Ciência e Tecnologia 21(2), 279-309.

Sagar, A., Daemmrich, A. and Ashiya, M. (2000) The tragedy of the commoners: biotechnology and its publics. Nature Biotechnology 18(January), 2-4.

Schmoldt, D. and Peterson, D. (1998) Analytical group decision-making in natural resources: methodology and application. Forest Science 46(1), 62-75.

Skorupinski, B. (2001) Debating novel food: a comparison of public participation processes on genetically modified food in four European countries. In: Third Congress of the European Society for Agricultural and Food Ethics, Florence, 3-5.10.2001, pp. 381-384.

Skorupinski, B. (2004) Debating risks and hazards - about deliberation and deliberate release. In: Breckling, B. and Verhoeven, R. (eds) Risk Hazard Damage: Specification of Criteria to Assess Environmental Impact of Genetically Modified Organisms, Naturschutz und Biologische Vielfalt, Vol. 1. Federal Agency for Nature Conservation, Bonn, Germany, pp. 171-182. 
Stern, P. and Fineberg, H. (eds) (1996) Understanding Risk: Informing Decisions in a Democratic Society. Committee on Risk Characterization. Commission on Behavioural and Social Sciences and Educations. National Research Council. National Academies Press, Washington, DC.

Susskind, L., McKearnan, S. and Thomas-Larmer, J. (eds) (1999) The Consensus Building Handbook: A Comprehensive Guide to Reaching Agreement. Sage Publications, Thousand Oaks, California.

Susskind, L., Levy, P.F. and Thomas-Larmer, J. (2000) Negotiating Environmental Agreements: How to Avoid Escalating Confrontation, Needless Costs, and Unnecessary Litigation. Island Press, Washington, DC.

Traynor, P.L., Fredrick, R.J. and Koch, M. (2002) Biosafety and Risk Assessment in Agricultural Biotechnology. A Workbook for Technical Training. The Agricultural Biotechnology Support Project. Institute of International Agriculture, Michigan State University, Michigan.

UNEP-GEF (2003a) Report of the subregional workshops for Asian countries on: Risk assessment and management and public awareness and participation. UNEP-GEF Project on Development of National Biosafety Frameworks, Asian Countries Subregional Workshop (January 21-24 2003, Kuala Lumpur, Malaysia). UNEPGEF Biosafety Unit, Geneva, Switzerland.

UNEP-GEF (2003b) Sub-regional workshop for Latin American countries on: Development of a regulatory regime and administrative systems. UNEP-GEF Project on Development of National Biosafety Frameworks, Latin American SubRegional Workshop on Development of a Regulatory Regime and Administrative Systems (November 25-28 2003, Santiago, Chile). UNEP-GEF Biosafety Unit, Geneva, Switzerland.

Wondolleck, J.M. and Yaffee, S.L. (2000) Making Collaboration Work: Lessons from Innovation in Natural Resource Management. Island Press, Washington, DC. 